\title{
Para uma educação inclusiva das minorias sexualmente distintas: a relevância da formação dos professores.
}

Sandra Maria Fodra ${ }^{1}$

RESUMO

Pesquisas recentes demonstram que o bullying homofóbico, ocorrido principalmente nas escolas, é responsável pelo sofrimento de jovens em vários países. Os educadores não abordam esses assuntos e dizem que, nas escolas onde trabalham não há casos de discriminação. Eles não se sentem à vontade para tratar de temas como homossexualidade, orientação e diversidade sexual. A escola é um espaço privilegiado para a convivência com as diversidades, para discussão sobre o preconceito, além da aprendizagem com a resolução de conflitos; mas é onde mais acontecem casos de intolerância de forma velada. Embora existam leis e orientações sobre o tema, ainda há um grande despreparo dos educadores e repertório adequado para tratar destas questões. Este é um problema emergente da Educação, pois os tabus e o desrespeito são reproduzidos na própria escola, promovendo a evasão de alunos. É necessário investir em formação e espaços para discussão sobre a sexualidade no cotidiano escolar.

Palavras-chave: homofobia - despreparo dos educadores - evasão escolar formação de professores

\begin{abstract}
Recent researches shows that homophobic bullying, mainly occurred in schools, is responsible for youth suffering in several countries. Educators do not address these issues and say that in schools where they work there are no cases of discrimination. They do not feel comfortable dealing with issues such as homosexuality, sexual orientation and diversity. The school is a privileged space for living with diversity, for discussion of prejudice, beyond learning to resolve conflicts; but it is where more cases of intolerance happens in a veiled way. Although there are laws and guidelines on the subject, there is still a great lack of preparation of teachers and appropriate repertoire to address these issues. This is an emerging issue of education, because taboos and disrespect are reproduced at the school, promoting the dropout of students. It is necessary to invest in training and spaces for discussion of sexuality in everyday school life.
\end{abstract}

Keywords: homophobia - unpreparedness of educators - absenteeism - teacher training

1 Possui graduação em Comunicação Social pelo Centro Universitário das Faculdades Integradas Alcântara Machado (1983) e graduação em História pela Universidade Braz Cubas (1995). Atualmente é membro da equipe do Programa Ensino Integral na Secretaria estadual de educação e mestranda em Educação - Currículo na Pontifícia Universidade Católica. Email: sandra.fodra@gmail.com 


\section{Introdução}

Um estudo desenvolvido por várias organizações internacionais e compilado pela UNESCO - conhecido por Consulta Internacional sobre o Bullying Homofóbico - deu origem a uma publicação chamada "Respostas do Setor de Educação ao Bullying Homofóbico". Esta obra trata da discriminação e sofrimento vivenciados por estudantes no mundo todo devido à homofobia. Há depoimentos de jovens que abandonaram os estudos por não suportarem mais situações de humilhação, desrespeito e até violência física na escola, pelo fato de terem uma orientação sexual que foge do padrão da 2"heteronormatividade". Segundo os relatos, os próprios gestores e educadores excluem os alunos ${ }^{3}$ LGBT por meio de apelidos vexatórios e trato diferenciado dos demais estudantes. Há inclusive relatos de jovens que tiveram negado o acesso à escola. As consequências do preconceito são desumanas, como se observa no trecho abaixo:

Evidências claras obtidas em muitos países mostram que a exposição ao bullying homofóbico provoca:

- Redução da frequência escolar

- Abandono escolar precoce

- Queda de desempenho e rendimento acadêmico

O bullying homofóbico, particularmente quando os alunos são intimidados, ridicularizados em público e roubados, está fortemente associado à evasão escolar. Em alguns casos, os alunos faltam às aulas ou fingem estar doentes para não ter que admitir a perda de livros, equipamentos ou dever de casa. Toda homofobia e o bullying homofóbico minam as oportunidades educacionais e de aprendizagem. (UNESCO, 2013, p.20)

Além dos mencionados acima, outros problemas podem ser desencadeados nas pessoas que sofrem bullying homofóbico na escola, como depressão, ansiedade, perda de confiança, retração, isolamento social, culpa e distúrbios do sono. Muitos pensam em se machucar (praticar a automutilação) e podem chegar ao suicídio. Há uma tendência ao uso abusivo de bebidas alcoólicas e envolvimento com drogas.

\section{A escola como locus de convivência com as diversidades}

A escola é um espaço privilegiado para o convívio com as diversidades, pois é nela que as crianças encontram os primeiros amigos e têm a oportunidade de desenvolver, ao longo da educação básica, habilidades de convivência e tomarem consciência da

2 Padrão de relacionamento sexual entre homem e mulher, desconsiderando as relações homossexuais.

3 Lésbicas, Gays, Bissexuais, Transexuais, Travestis e Transgêneros. 
interdependência entre todas as pessoas. Sem falar que a educação é um direito de todos e a principal função da escola é de formação plena e integral de todos os seus alunos.

Estamos falando, portanto, da formação e da instrução das pessoas visando a sua instrumentalização para a participação motivada e competente na vida política e pública. Ao mesmo tempo, entendo que essa formação deve visar também ao desenvolvimento de competências para lidar com a diversidade e o conflito de ideias, com as influências da cultura e com os sentimentos e emoções presentes nas relações do sujeito consigo mesmo e com o mundo à sua volta. (ARAÚJO, 2000, p.96).

Quando os jovens são privados de frequentar a escola, eles perdem a possibilidade do desenvolvimento intelectual, emocional, social e cultural. A formação proporcionada pela escola permite a ampliação de inúmeras habilidades que contribuem para o seu desenvolvimento pessoal e preparam para o ingresso na vida adulta. Inserir-se no mercado de trabalho é outra conquista que se torna praticamente impossível de ser realizada, já que a formação básica e a qualificação profissional são as bases para viabilizar qualquer emprego digno.

Como viver no mundo moderno, onde são exigidas tantas competências, sem frequentar uma escola e, posteriormente, um curso profissionalizante ou uma universidade? Esta situação contribui para reprodução da miséria, da ignorância e proliferação dos problemas sociais. Grande parte dos homossexuais acaba se prostituindo para sobreviver, e tem seu direito à educação privado devido ao preconceito e à discriminação que, infelizmente, ainda estão presentes em muitos países.

\section{A escola como instituição reprodutora da homofobia}

No Brasil, a situação não é diferente, como demonstra um estudo realizado com base no questionário do Exame Nacional do Ensino Médio (ENEM) entre 2004 e 2008, cujos resultados foram veiculados no jornal "O Estado de São Paulo":

Um levantamento inédito, feito com base no questionário socioeconômico do Exame Nacional do Ensino Médio (Enem), entre 2004 e 2008, mostra um crescimento de $160 \%$ no número de pessoas que se declararam vítimas de homofobia no Estado de São Paulo.

O índice é superior à média do País, cujo aumento foi de $150 \%$, e coloca o Estado na lista dos cinco mais homofóbicos do Brasil - atrás de Santa Catarina (211\%), Paraná (175\%), Rio Grande do Norte $(162,5 \%)$ e Alagoas (164,7\%).

Em 2004, 1,5\% dos estudantes paulistas afirmou ter sofrido preconceito por causa de sua orientação sexual. Quatro anos depois, o porcentual 
passou para 3,9\%. Foram analisadas as respostas de 6,4 milhões de estudantes concluintes do ensino médio, com idades entre 16 e 25 anos, que prestaram o Enem entre 2004 e 2008. Após esse ano, as questões relativas à homofobia foram retiradas dos questionários. (O ESTADO DE SÃO PAULO, 19/06/2011)

Para Fernando Teixeira, Professor de Psicologia na Universidade Estadual Paulista e pesquisador das diversidades sexuais, a escola reforça o discurso e reafirma os valores heterossexuais como sendo a única forma socialmente aceitável de "manifestação da sexualidade", conforme explica no trecho extraído de uma pesquisa realizada com jovens estudantes em três cidades do interior de São Paulo:

Comumente, as sexualidades ditas não-hegemônicas são desvalorizadas e hostilizadas, o que causa sofrimento e dor a quem não corresponde aos padrões heteronormativos. Assim, verificou-se que, em cada categoria específica do agrupamento não-heterossexual, ${ }^{4} @$ s mais assumid@s (gays e lésbicas) são@s que mais sofrem discriminação e violência homofóbica. Porém, não menos expressivo foi o número de bissexuais e outros também vitimados pela homofobia. Dentre aqueles que se identificaram nesta última categoria, há certa relação entre manifestações homofóbicas e o ato de assumir uma identidade não-heterossexual. Isto é,@s assumid@s pensam menos em suicídio e tentam menos se matar comparativamente àquel@s não assumid@s, mas sofrem mais discriminação e violência homofóbica. (TEIXEIRA, 2011, p.737)

Nas respostas dadas pelos alunos LGBT que participaram da pesquisa, é possível notar o sofrimento que eles sentem por terem desejos sexuais considerados inadequados. A autorrejeição e o isolamento pelo fato de sentirem-se diferentes e não serem aceitos socialmente geram conflitos internos que os acompanham pela vida inteira.

Desde pequenin@s, aprendemos (mesmo sem saber o que isso significa) que ser gay, lésbica etc., é algo ruim e não desejável. Mais do que saber sobre isso, para quem tem consciência desde muito cedo de sua atração por pessoas do mesmo sexo ou de se sentir pertencendo ou atraíd@, por coisas e situações que dizem respeito a outro gênero, trata-se de se sentir desvalorizad@. (TEIXEIRA, 2011,p.729)

Em sua pesquisa, Teixeira afirma a necessidade da revisão dos valores reproduzidos nas escolas para que, de fato, estas instituições possam garantir os direitos essenciais e a dignidade humana a toda comunidade escolar, principalmente à população LGBT. Tanto os educadores quanto os alunos homossexuais são discriminados e sofrem humilhações no ambiente escolar. A maioria deles nem reclama porque não acredita que alguém possa $4 @$ substituindo as vogais "a" ou "o" indica neutralidade de gênero. 
enxergar a situação como desumana; isso já está banalizado.

\section{A escola como instituição mediadora dos conflitos}

Considerar e atender as necessidades e os interesses de todos não é tarefa simples, mas os educadores precisam buscar alternativas que minimizem os conflitos internos e externos causados pela supervalorização da heteronormatividade (ou outro conflito que caracterize desrespeito humano). O desejo sexual de uns jamais deverá incomodar os outros. A criação de espaços para a discussão dos conflitos e exposição dos sentimentos dos envolvidos costuma ser uma ação assertiva para resolver essas questões. Por mais que seja difícil abordar temas polêmicos e conflitantes em sala de aula, é necessário que se faça, pois permitirá que cada aluno manifeste seu ponto de vista e garantirá a liberdade de expressão e a reflexão a partir da opinião alheia, inclusive dos educadores.

Atualmente, um dos objetivos centrais da educação é a formação de cidadãos e cidadãs, o que implica dizer que as escolas devem buscar a equidade e o respeito entre as pessoas. Essa não é apenas uma questão pedagógica, mas também política. No entanto, as escolas têm dificuldades em compatibilizar, a contento, a complexa relação entre políticas públicas de educação e demandas sociais, pelo menos no que diz respeito às que tratam de igualdade de gêneros, minimização da homofobia, prevenção às DST/HIV-AIDS, direitos humanos e temas correlatos. Abordar esses temas torna-se conflitante, pois, inevitavelmente, a escola deverá negociar entre aquilo que as políticas públicas e as leis acreditam ser a direção possível para a produção de cidadãos e cidadãs livres, crític@s e instruíd@s, e aquilo que@s professor@s, em suas crenças e valores pessoais, e as famílias, em seus agrupamentos e/ou isoladas, esperam para a educação de seus/suas filh@s. Trata-se, portanto, de equacionar interesses individuais que se contrapõem aos coletivos. (TEIXEIRA, 2011, p. 727)

Recentemente, o Sindicato dos Professores do Ensino Oficial do Estado de São Paulo (APEOESP) realizou uma pesquisa com o objetivo de avaliar a qualidade da escola pública, e a questão da discriminação e da violência no ambiente escolar veio à tona.

O estudo teve uma abordagem quantitativa - foram entrevistadas 2100 pessoas, 700 professores, 700 pais de alunos e 700 alunos - e qualitativa com grupos de discussão também envolvendo professores, pais de alunos e alunos.

Os resultados mostram que há uma inadequação entre a formação oferecida pelas escolas e as necessidades reais dos alunos, falta de segurança e de respeito, e que o preconceito e a discriminação principalmente à população LGBT, acontecem com frequência. 
No quadro abaixo estão somente as informações relacionadas à discriminação contra alunos:

No quesito "discriminação contra os alunos", obteve-se os seguintes resultados:

\begin{tabular}{|c|c|c|c|}
\hline \multicolumn{3}{|c|}{ Soube que aconteceu ou presenciou casos de discriminação contra alunos } \\
\hline & PROFESSORES & PAIS & ALUNOS \\
\hline HOMOSSEXUAL & $36 \%$ & $17 \%$ & $35 \%$ \\
\hline NEGRO & $29 \%$ & $19 \%$ & $33 \%$ \\
\hline NORDESTINO OU DESCENDENTE & $18 \%$ & $7 \%$ & $13 \%$ \\
& & & \\
\hline POBRE & & & \\
\hline DEFICIENTE FISICO & $16 \%$ & $8 \%$ & $17 \%$ \\
\hline MULHER & $12 \%$ & $4 \%$ & $10 \%$ \\
\hline
\end{tabular}

http://www.apeoesp.org.br/publicacoes/opiniao-apeoesp/pesquisa-apeoesp-data-popular/ p. 16

Embora existam leis e documentos oficiais que visam a regulamentação e a orientação do trabalho educacional desenvolvido nas escolas, a prática e a banalização de atos discriminatórios são cotidianas nestas instituições.

\section{Legislação e orientações oficiais para a educação cidadã}

A Lei de Diretrizes e Bases (LDB) foi criada em 1996, visando garantir uma educação de qualidade, democrática e com formação cidadã para todos os brasileiros. Dentre os princípios que devem embasar o ensino, previstos nesta lei estão:

Art. $3^{\circ}$. O ensino será ministrado com base nos seguintes princípios:

I - Igualdade de condições para o acesso e permanência na escola;

II - Liberdade de aprender, ensinar, pesquisar e divulgar a cultura, o pensamento, a arte e o saber;

III - Pluralismo de ideias e de concepções pedagógicas;

tolerância;

IV - Respeito à liberdade e apreço à

Em 1997, o Ministério da Educação e Cultura divulgou os Parâmetros Curriculares Nacionais (PCN) contendo os temas transversais, como Saúde, Ética, Sexualidade, Educação Ambiental, dentre outros, prevendo que estes temas fossem abordados nas escolas, perpassando por todas as disciplinas do currículo e criassem espaços para 
discussão e conscientização dos alunos. Sobre o tema Orientação Sexual, este documento explica:

A Orientação Sexual na escola deve ser entendida como um processo de intervenção pedagógica que tem como objetivo transmitir informações e problematizar questões relacionadas à sexualidade, incluindo posturas, crenças, tabus e valores a ela associados. Tal intervenção ocorre em âmbito coletivo, diferenciando-se de um trabalho individual, de cunho psicoterapêutico e enfocando as dimensões sociológica, psicológica e fisiológica da sexualidade. Diferencia-se também da educação realizada pela família, pois possibilita a discussão de diferentes pontos de vista associados à sexualidade, sem a imposição de determinados valores sobre outros. O trabalho de Orientação Sexual visa propiciar aos jovens a possibilidade do exercício de sua sexualidade de forma responsável e prazerosa. Seu desenvolvimento deve oferecer critérios para o discernimento de comportamentos ligados à sexualidade que demandam privacidade e intimidade, assim como reconhecimento das manifestações de sexualidade passíveis de serem expressas na escola. Propõem-se três eixos fundamentais para nortear a intervenção do professor: Corpo Humano, Relações de Gênero e Prevenção às Doenças Sexualmente Transmissíveis/AIDS. (PCN, 1997, p.28)

Outro documento norteador para o trabalho docente nas escolas de educação básica é o Plano Nacional de Educação em Direitos Humanos (PNEDH - 2007) que declara que "a Educação deve contribuir para o respeito às diversidades e promoção de uma cultura de direitos humanos“.

Nos termos já firmados no Programa Mundial de Educação em Direitos Humanos, a educação contribui também para:

a) criar uma cultura universal dos direitos humanos;

b) exercitar o respeito, a tolerância, a promoção e a valorização das diversidades (étnico-racial, religiosa, cultural, geracional, territorial, físico-individual, de gênero, de orientação sexual, de nacionalidade, de opção política, dentre outras) e solidariedade entre povos e nações;

c) assegurar a todas as pessoas o acesso à participação efetiva em uma sociedade livre. (PNEDH, 2007, p. 25)

Além dos documentos acima citados, que deveriam garantir o acesso à escola e o respeito às diversidades, também existem leis que criminalizam as práticas discriminatórias em relação à orientação sexual, como a Lei n. ${ }^{\circ}$ 10.948/2001, que "dispõe sobre as penalidades a serem aplicadas à prática de discriminação em razão de orientação sexual", bem como que estabelecem diretrizes para o tratamento, pelos órgãos públicos, das pessoas transexuais e travestis, como o Decreto $\mathrm{n}^{\circ} 55.588 / 2010$ do Estado de São Paulo. 
Questões relacionadas à sexualidade estão disponíveis ainda em revistas, livros, sites, pesquisas científicas e outros inúmeros recursos, mas o preconceito sobre o assunto ainda impede que eles sejam lidos e amplamente discutidos na maior parte das instituições de ensino. Esses materiais são distribuídos nas escolas, mas geralmente ficam guardados porque incomodam os educadores mais conservadores.

\section{Pesquisa com professores da rede estadual paulista sobre materiais que tratam da sexualidade}

Um estudo sobre o uso de materiais didáticos que orientam as ações escolares acerca do tema sexualidade mostrou que estes materiais não são conhecidos e muito menos usados pelos educadores.

Professores de três regiões da capital paulista participaram de uma pesquisa, realizada por esta autora em 2012, sobre o trabalho desenvolvido com temas relacionados à sexualidade nas escolas que atuam. Os resultados mostraram o despreparo desses educadores tanto no conhecimento dos temas, quanto na abordagem que têm, junto aos alunos. $\mathrm{O}$ assunto sexualidade não é tratado na maior parte das escolas, e quando é abordado, sempre está impregnado de tabus e restrições, não atendendo às reais necessidades dos alunos no que tange a conscientização e formação ética.

O objetivo da pesquisa foi fazer um levantamento dos materiais didáticos sobre sexualidade e diversidade de gênero existentes nas escolas, seu uso durante as aulas, se a comunidade escolar resiste a discussões sobre o assunto e como os gestores da escola atuam nos casos de homofobia. Os 54 professores participantes responderam um questionário com apenas dez perguntas e as respostas foram compiladas por eixos temáticos.

\section{QUADRO SÍNTESE DAS RESPOSTAS DOS PROFESSORES}

\begin{tabular}{|l|l|}
\hline Discussão sobre sexualidade e diversidade sexual somente em algumas aulas & $57 \%$ \\
\hline Discussão sobre sexualidade e diversidade sexual nas HTPC & $8 \%$ \\
\hline Os temas sexualidade e diversidade sexual não são abordados na escola & $43 \%$ \\
\hline Os temas sexualidade e diversidade sexual não devem ser tratados na escola & $11 \%$ \\
\hline Acham que é importante discutir sexualidade e diversidade sexual na escola & $89 \%$ \\
\hline Não conhecem materiais didáticos sobre sexualidade e diversidade sexual & $73 \%$ \\
\hline
\end{tabular}

Os resultados foram surpreendentes, pois demonstraram a falta de conhecimento e repertório adequado para tratar do tema sexualidade e, principalmente, sobre diversidade 
de gênero.

Quanto à utilização dos materiais e abordagem do tema, 57\% dos professores declarou que a questão da diversidade sexual é discutida na escola apenas em algumas aulas, mas sem aprofundamento no assunto para não gerar polêmica; $8 \%$ acrescentou que as discussões também chegam às reuniões semanais que os professores da Rede Estadual de São Paulo participam (Horas de Trabalho Pedagógico Coletivo - HTPC), porém há muito preconceito das pessoas. Já $43 \%$ dos entrevistados respondeu que o assunto não é abordado e $11 \%$ acrescentou que esse assunto não deve ser discutido na escola.

Vale a pena lembrar que fazem parte do Currículo do Estado de São Paulo para o Ensino Médio, conteúdos relacionados aos direitos humanos, diversidade sexual e violência simbólica. Há várias situações de aprendizagem que visam a promoção de conhecimentos e reflexões sobre esses temas, principalmente nas aulas das disciplinas de Ciências Humanas.

Uma das perguntas feitas aos professores foi sobre a importância de discutir com os alunos a questão da diversidade de gênero, e $89 \%$ respondeu que é muito importante esse tipo de discussão, mas as justificativas dadas sobre o porquê da importância demonstraram que há uma superficialidade ou total desconhecimento do significado das expressões "diversidade sexual" e "orientação sexual". Oito entrevistados $(14,8 \%)$ usaram a gravidez precoce como justificativa para a necessidade das discussões. Apenas 5 professores $(9,2 \%)$ falaram sobre o respeito à diversidade e sexo seguro; e somente um reconhece que os educadores não têm formação adequada para discutir o assunto. Os educadores confessam que não se sentem à vontade para conversar sobre esses temas com seus alunos.

Os resultados da pesquisa foram usados como pauta para reuniões de formação e discussão com alguns dos professores entrevistados. A princípio, os docentes sentiam-se pouco à vontade para falar sobre o assunto ou contar algum episódio em que a discriminação aparecia na escola. A apresentação de algumas reportagens e vídeos sobre a homofobia sensibilizou-os e motivou o início de um diálogo em que eles se sentiram à vontade para se posicionarem sobre o assunto, e começarem a refletir sobre as consequências que ignorar ou permitir a banalização da discriminação e dos conflitos (que podem se transformar em atos de violência) trazem para a sociedade.

O conflito é parte natural de nossas vidas e apenas isto já seria suficiente para considerá-lo como importante tema de estudo. De fato, todas as teorias interacionistas em filosofia, psicologia e educação estão alicerçadas no pressuposto de que nos constituímos e somos constituídos a partir da relação direta ou mediada com o outro, seja ela de natureza subjetiva ou objetiva. Nessa relação, nos deparamos com as diferenças e semelhanças que nos obrigam a comparar, descobrir, 
ressignificar, compreender, agir, buscar alternativas e refletir sobre nós mesmos e sobre os demais. O conflito torna-se, portanto, a matéria prima para nossa constituição psíquica, cognitiva, afetiva, ideológica e social. (ARAÚJO, 2008, p.115)

A criação de espaços de formação, reflexão e discussão sobre os conflitos e as situações de vulnerabilidade nas escolas são imprescindíveis para que os educadores e gestores tratem com mais respeito e humanidade as situações de preconceito e discriminação.

\section{Ações da Secretaria de Estado da Educação de São Paulo (SEE) para uma formação que respeite as diferenças e as necessidades dos estudantes}

A Secretaria de Estado da Educação de São Paulo criou algumas políticas públicas nos últimos anos, visando diminuir os conflitos, o preconceito com as diversidades e a violência nas escolas paulistas, além de ampliar o acesso e a permanência dos alunos até o final da educação básica. O objetivo é oferecer uma escola de qualidade e ampliar as oportunidades de formação a todos os alunos, a partir das suas necessidades, permitindo que eles se sintam pertencentes e participantes das ações da escola. A Secretaria visa introduzir uma nova concepção de educação, onde o aluno encontre sentido e significado na sua formação e dê continuidade aos seus estudos, seja por meio de cursos profissionalizantes ou universitários.

\section{O Programa Ensino Integral}

A criação do Programa Ensino Integral é uma das ações que oferece ensino integral em período integral e pretende qualificar os espaços de formação dos alunos, conforme descrito nas suas Diretrizes:

É fundamental destacar que, para a SEE-SP, a educação integral deve ser assegurada a todos os alunos da Rede estadual, embora a jornada ampliada ofereça mais condições para o desenvolvimento das habilidades requeridas para a plena escolaridade. Essa circunstância pode favorecer a aprendizagem de outras competências além das cognitivas, como, por exemplo, o desenvolvimento de projetos com forte presença da participação e do protagonismo dos alunos e a vivência de valores necessários para a vida. Diante dessa perspectiva, a SEE-SP vem implantando uma política educacional que redefine o papel da escola, consolidando-a como instituição democrática, inclusiva, com a responsabilidade de promover a permanência e o sucesso na aprendizagem. (DIRETRIZES DO PROGRAMA ENSINO 
O Programa Ensino Integral, implementado em 2012 em 16 escolas piloto de Ensino Médio, trouxe inovações no conteúdo, método e gestão, e também ampliou a participação e responsabilização dos alunos em todas as ações desenvolvidas na escola. O objetivo do Programa é formar jovens autônomos, solidários e competentes com um "Projeto de Vida" construído até o final do Ensino Médio. O foco do trabalho docente e a parte diversificada do currículo utilizado nas escolas convergem para as necessidades dos alunos e para a realização do seu Projeto de Vida, estimulando-os à continuidade dos estudos. As aulas de Orientação de Estudos, a Tutoria desenvolvida pelos professores, as Disciplinas Eletivas (projetos interdisciplinares criados a partir dos desejos dos alunos) e os Clubes Juvenis são diferenciais que estimulam e dão significado à aprendizagem. Os alunos da última série da educação básica têm aulas de Preparação para o Mundo do Trabalho e Preparação Acadêmica, disciplinas que oferecem subsídios para o ingresso em universidades e entrada no mercado de trabalho.

Há um grande investimento nas ações de formação oferecidas aos professores e gestores das escolas. Eles recebem formação inicial e continuada sobre as metodologias inovadoras do Programa e passam por avaliação de desempenho todos os anos. Esta avaliação tem por objetivo levantar as necessidades de formação dos profissionais, a partir das competências esperadas, e propor um Plano Individual de Aprimoramento Profissional, conhecido por PIAF. Todos exercem o princípio da "Pedagogia da Presença", com trabalho em período integral e atendimento às necessidades dos alunos. Os resultados positivos tanto nas avaliações internas quanto nas externas já são visíveis. O Índice de Desenvolvimento da Educação do Estado de São Paulo (IDESP) aponta um crescimento nas escolas de Ensino Médio do Programa de 26\% em 2012, de 24\% em 2013 e de 26\% em 2014. Estes são índices de melhoria muito significativos para esta etapa da educação básica, em que a evasão e a retenção dos alunos são expressivas.

O ambiente das escolas que participam deste Programa é tranquilo e acolhedor; os alunos e professores convivem numa relação de cumplicidade e respeito mútuo. Os alunos formados nestas escolas recebem todo apoio dos educadores para darem continuidade aos seus estudos, e assim, materializarem seus Projetos de Vida.

Atualmente, existem 293 escolas participantes do Programa Ensino Integral que atendem aproximadamente 80.000 alunos do Ensino Fundamental - Anos Iniciais, Anos Finais e do Ensino Médio, tanto na capital quanto no interior do estado de São Paulo.

\section{O Projeto Professor Mediador Escolar e Comunitário}


Outra ação que merece destaque como política pública da SEE é o Projeto Professor Mediador Escolar e Comunitário. Este projeto foi implementado em $2010 \mathrm{com}$ o objetivo de criar nas escolas uma cultura de paz e de resolução dos conflitos por meio do diálogo amigável e ético. Os professores, designados Mediadores, recebem formação inicial e continuada sobre como mediar conflitos e criar projetos interdisciplinares com temas transversais, a partir das necessidades encontradas no ambiente escolar. Mensalmente, os Professores Mediadores participam de um encontro de formação nas Diretorias Regionais de Ensino, coordenados pelos gestores regionais, onde podem trocar experiências exitosas e estudar formas de melhorar o ambiente escolar e minimizar as vulnerabilidades existentes. São atribuições dos Professores Mediadores nas escolas, previstas na Resolução SE no 07, de 19-1-2012:

I - Adotar práticas de mediação de conflitos no ambiente escolar e apoiar o desenvolvimento de ações e programas de Justiça Restaurativa;

II - Orientar os pais dos alunos, ou responsáveis, sobre o papel da família no processo educativo;

III - analisar os fatores de vulnerabilidade e de risco a que possam estar expostos os alunos;

IV - Orientar a família, ou responsáveis, quanto à procura de serviços de proteção social;

$\mathrm{V}$ - Identificar e sugerir atividades pedagógicas complementares, a serem realizadas pelos alunos fora do período letivo;

VI - Orientar e apoiar os alunos na prática de seus estudos.

O monitoramento das ações desenvolvidas pelos Professores Mediadores demonstra que o número de ocorrências escolares diminuiu e as relações interpessoais melhoraram sensivelmente. As pessoas se acostumaram a discutir sobre os conflitos existentes e resolverem entre os próprios envolvidos, muitas vezes, sem a necessidade de participação do Professor Mediador.

Segundo as autoras espanholas Genoveva Sastre e Montserrat Moreno,

Formar os(as) alunos(as), desenvolver sua personalidade, fazêlos(as) conscientes de suas ações e das consequências que acarretam, conseguir que aprendam a conhecer melhor a si mesmos(as) e às demais pessoas, fomentar a cooperação, a autoconfiança e a confiança em suas companheiras e seus companheiros, com base no conhecimento da forma de agir de cada pessoa, e a beneficiar-se das consequências que estes conhecimentos lhes proporcionam. A realização destes objetivos leva a formas de convivência mais satisfatórias e a melhoria da qualidade de vida das pessoas, qualidade de vida que não se baseia no consumo, e sim em gerir adequadamente os recursos mentais... intelectuais e emocionais - para alcançar uma convivência humana 
muito mais satisfatória. (2005, p.58).

Considerar os conflitos escolares como uma oportunidade para a aprendizagem emocional e de responsabilização pelas consequências das suas ações é a melhor forma que os educadores têm para formar cidadãos éticos e responsáveis. A conscientização (tanto do corpo docente quanto do discente) sobre as consequências das atitudes preconceituosas e o trabalho de mediação dos conflitos foram decisivos para a criação de um ambiente tranquilo, em que todos possam se sentir seguros e respeitados. É a comprovação do surgimento de uma nova cultura, demonstrando que a existência de uma escola agradável, humana e que atenda as expectativas dos alunos é possível.

\section{O Núcleo de Inclusão - NINC}

A Secretaria de Educação criou também um Núcleo de Inclusão Educacional que é responsável pelo desenvolvimento de estudos e estratégias que garantam a inclusão das minorias, além de promover a formação de docentes. O objetivo é assegurar o ingresso, a permanência e a formação de todas as crianças, jovens e adultos nas escolas paulistas, até a conclusão da educação básica, independente da raça, orientação sexual, idade ou nacionalidade.

Sobre o tema orientação sexual, o Núcleo de Inclusão Educacional criou o Plano Estadual de Enfrentamento à Homofobia, com metas e ações estabelecidas pela Secretaria da Educação que orientam os educadores e gestores a identificar e resolver os casos de homofobia nas escolas paulistas, de forma respeitosa e responsável, além de garantir o direito à educação à população LGBT. As metas do plano são:

- META 1: Formação dos servidores sobre diversidade sexual.

- $\quad$ META 2: Atendimento pautado pelo reconhecimento dos direitos das populações LGBT.

- $\quad$ META 3: Articulação com vistas à sensibilização da comunidade escolar.

- $\quad$ META 4: Currículo, práticas e materiais pedagógicos com ampliação da temática.

- $\quad$ META 5: Monitoramento das ações para implementação e execução do plano.

O Núcleo de Inclusão veiculou uma série de videoconferências e disponibilizou 
materiais orientadores para o trabalho dos educadores a fim de consolidar a inclusão das minorias (étnicas, de gênero, de orientação sexual, nacionalidade, dentre outras) nas escolas paulistas de forma respeitosa e responsável.

\section{A formação dos profissionais como pressuposto da igualdade e equidade nas escolas públicas paulistas}

A Secretaria também tem subsidiado cursos de mestrado e doutorado para professores e gestores das escolas da rede, oferecendo bolsas de estudo e incentivos salariais, visando a melhor qualificação desses profissionais na atuação docente e melhoraria da qualidade do ensino oferecido nas escolas públicas. Nestes cursos os educadores têm a oportunidade de aprofundar seus conhecimentos sobre temas e metodologias de ensino por meio de pesquisas científicas e leituras de autores renomados acerca dos processos de ensino, aprendizagem e avaliação. São investimentos que objetivam uma gestão eficaz nas escolas, além de tornar as aulas mais significativas e atraentes, contribuir para o acesso e permanência dos estudantes na escola e ainda despertar seu desejo para a continuidade dos estudos após a conclusão da educação básica.

Todas as ações implementadas pela Secretaria Estadual de Educação de São Paulo visam à preparação dos alunos da rede para o exercício da cidadania e atuação na vida adulta de forma responsável e consciente. A finalidade é oferecer uma educação de qualidade, num ambiente seguro, em que os alunos se sintam acolhidos, pertencentes e participantes (principalmente os pertencentes às minorias excluídas); e que deem continuidade aos seus estudos no futuro, rompendo com os ciclos de pobreza e exclusão que permeiam nossa história. Este é o melhor caminho para a construção de uma sociedade mais justa, inclusiva e ética.

\section{REFERÊNCIAS}

APEOESP. Qualidade da Educação nas escolas Estaduais de São Paulo. São Paulo, 2014. Disponível em: http://www.apeoesp.org.br/publicacoes/opiniao-apeoesp/ pesquisa - Acesso em 12 de julho de 2014.

ARAUJO, Ulisses. Escola, democracia e a construção de personalidades morais. São Paulo, 2000. Disponível em:

http://www.redalyc.org/articulo.oa?id=29826207 - Acesso em 03 de outubro de 2015.

ARAUJO, Ulisses. Resolução de conflitos e assembleias escolares. Disponível em: http://periodicos.ufpel.edu.br/ojs2/index.php/caduc/article/view/1743/1623 - Acesso em 03 de outubro de 2015.

FODRA, Sandra Maria. Materiais didáticos para uma educação inclusiva, 2012, 
Salvador. VI Congresso Internacional de Estudos sobre a Diversidade Sexual e de Gênero da ABEH.

O ESTADO DE SÃO PAULO (OESP). Homofobia na escola cresce 160\% em SP. Publicado em 19/06/2011, Vida, p. A28. São Paulo - Disponível em http://www2.senado. leg.br/bdsf/item/id/356058 - Acesso em 03 de outubro de 2015.

SASTRE, Genoveva; MORENO, Montserrat. Resolução de Conflitos e Aprendizagem Emocional. São Paulo. Moderna, 2005

TEIXEIRA, Fernando Silva; RONDINI, Carina Alexandra; BESSA Juliana Cristina Reflexões sobre homofobia e educação em escolas do interior paulista. São Paulo, 2011. Disponível em:

http://www.scielo.br/scielo.php?script=sci_arttext\&pid=S1517-9702201100040 Acesso em 12 de julho de 2014.

UNESCO. Respostas do Setor de Educação ao Bullying Homofóbico - 2013. Disponível em: http://unesdoc.unesco.org/images/0022/002213/221314por.pdf - Acesso em 03 de outubro de 2014.

\section{DOCUMENTOS LEGAIS}

BRASIL. Ministério da Educação. Plano Nacional de Educação em Direitos Humanos / Comitê Nacional de Educação em Direitos Humanos. - Brasília: Secretaria Especial dos Direitos Humanos, Ministério da Educação, Ministério da Justiça, UNESCO, 2007.

BRASIL, Brasília. Lei $\mathrm{n}^{\circ}$ 9.394, de 20 de dezembro de 1996. Estabelece as diretrizes e bases da educação nacional. Diário Oficial da República Federativa do Brasil de 23/12/1996, P. 27833.

BRASIL, Ministério da Educação e Cultura. Parâmetros Curriculares Nacionais Brasília, 1997.

BRASIL, São Paulo - Lei No 10.948, de 5 de novembro de 2001 - Dispãe sobre as penalidades a serem aplicadas à prática de discriminação em razão de orientação sexual e dá outras providências. Diário Oficial v.111, n.209, 06/11/2001.

SÃO PAULO. Decreto $n^{0} 55.588$, de 17 de março de 2010. Dispõe sobre o tratamento nominal das pessoas transexuais e travestis nos órgãos públicos do Estado de São Paulo e dá providências correlatas - Diário Oficial de 18 de março de 2010.

SÃO PAULO. Estado. Secretaria da Educação. Diretrizes do Programa Ensino Integral. São Paulo: SE, 2014. Disponível na INTRANET - Espaço do Servidor. Acesso em 27 de julho de 2015.

SÃO PAULO. Resolução SE $\mathrm{n}^{0}$ 07, de 19-1-2012 - Dispõe sobre o exercício das atribuições de Professor Mediador Escolar e Comunitário do Sistema de Proteção Escolar. Disponível em: http://siau.edunet.sp.gov.br/ItemLise/arquivos/07_12. HTM?Time=24/2012/03 -Acesso em 03 de outubro de 2015.esso em 12 de outubro de 2015. 